Article

\title{
OGC Consensus: How Successful Standards Are Made
}

\section{Carl Reed ${ }^{1, *}$, Kurt Buehler ${ }^{2}$ and Lance McKee ${ }^{3}$}

1 Carl Reed and Associates, Fort Collins, CO 80526, USA

2 Image Matters, LLC, 201 Loudoun St SW, Leesburg, VA 20175, USA;

E-Mail: kurtb@imagemattersllc.com

3 Open Geospatial Consortium, 35 Main Street, Suite 5, Wayland, MA 01778, USA;

E-Mail: 1mckee@ opengeospatial.org

* Author to whom correspondence should be addressed; E-Mail: carl.n.reed@ gmail.com; Tel.: +1-301-560-6439.

Academic Editor: Wolfgang Kainz

Received: 1 May 2015 / Accepted: 20 July 2015 / Published: 7 September 2015

\begin{abstract}
This paper describes the history, background, and current status of the Open Geospatial Consortium (OGC) standards development consensus process. The roots of the formation of the OGC lie in the early 1990s when a very strong market requirement for exchanging GIS data content was clearly stated. At that time, each GIS vendor had their own formats for publishing and/or exchanging their GIS data. There was no mechanism or organization that provided a forum for the GIS vendors and GIS data users to collaborate and agree on how to share GIS data. That requirement, along with the vision of a few individuals, led to the formation of the OGC. This paper describes the early development of the consensus process in the OGC, how this process has evolved over time, why consensus is so important for defining open standards that are implemented in the marketplace, and the future of the OGC consensus process.
\end{abstract}

Keywords: OGC; consensus; standards; geospatial; GIS

\section{Introduction}

This paper addresses the following topics:

- What is the Open Geospatial Consortium (OGC)? 
- Why the OGC: Historical Context?

- A bit of background and History

- What is Consensus?

- The OGC Technical Committee policies and Procedures

- Consensus and Intellectual Property

- What has been established and what's next?

\section{What is the OGC?}

The OGC provides a collaborative, consensus process for developing, approving and maintaining open, international standards that enable the modelling, sharing, and access to any location enabled content or service. "International standards" are those adopted by an international standardizing/standards organization, often referred to as an SDO, and made available to the public. More specifically, the OGC is a Voluntary Consensus Standards Organization. "Voluntary consensus standards bodies" are domestic or international organizations which plan, develop, establish, or coordinate voluntary consensus standards using agreed-upon procedures.

According to the US Government OMB Circular A-119 [1], a voluntary consensus standards body is defined (OMB Circular a-119 (1998) http://www.nist.gov/standardsgov/omba119.cfm\#4) by the following attributes:

- Openness.

- Balance of interest.

- Due process.

- An appeals process.

- Consensus, which is defined as general agreement, but not necessarily unanimity, and includes a process for attempting to resolve objections by interested parties, as long as all comments have been fairly considered, each objector is advised of the disposition of his or her objection(s) and the reasons why, and the consensus body members are given an opportunity to change their votes after reviewing the comments.

The above-stated characteristics are fundamental to the OGC policies and procedures framework and guidelines for the collaborative and consensus development of OGC standards. While the OMB circular definition suggests that consensus is a separate attribute, in reality how the organization views and operates with regard to openness, balance of interest, due process, and an appeals process are all fundamental aspects of an open consensus process.

\section{Why the OGC: Historical Context}

The roots of the OGC and its vision and mission start as early as 1986. A GIS group at MASSCOMP Computers led by David Schell and Lance McKee learned that the existing GIS market was as limited as the CAD market by the variety of proprietary and closed systems and data models. They began to see how many of the problems of geospatial data sharing could be solved by a more extensive use of a standard, open system such as UNIX. This is when Peter Burrough of the University of Utrecht, a user of MASSCOMP (https://en.wikipedia.org/wiki/MASSCOMP) systems and author of the first GIS 
textbook, suggested that we get in touch with Carl Reed, president of a small, UNIX-based vector-GIS company in Fort Collins called DeltaSystems. Within two weeks Carl and John Davidson had DeltaMap ported to a MASSCOMP system. David Schell then asked the seminal question: "Could DeltaMap plot vector data on a GRASS raster image without translating or moving data from one system to another?" Within weeks, John Davidson demonstrated running a common X-Window shared by both GRASS and DeltaMap. Users could access and display data from two different GIS systems into a common window - a very early web map server. This work would lead over the next few years to the definition of "Open GIS".

In the early 1990s, a series of US Federal GIS procurements occurred. In these procurements a mandatory requirement was the ability to read a specific vendor proprietary format. Intergraph, Genasys, and other GIS companies bid for these contracts. However, they were eliminated based on their inability to read and write the proprietary format.

This situation led to discussions in 1992 within a segment of the GIS community about how to promote and agree to technology for sharing GIS data. These discussions eventually lead to the formation of the Open GIS Consortium (now the Open Geospatial Consortium).

The platform or framework for these discussions was the Open Grass Foundation (OGF). The OGF was formed in 1992. In that year, Kurt Buehler worked with OGF to put together a series of industry technical meetings, and Kurt was assigned to develop the "Community Consensus" process. The first formal meeting to address this concept was hosted by the National Park Service in Lakewood, CO and attended by most of the major commercial GIS vendors. Additional meetings supported by the U.S. Army Construction Engineering Research Laboratory (CERL (http://www.erdc.usace.army.mil/ Locations/ConstructionEngineeringResearchLaboratory.aspx)) included meetings hosted by U.S. National Oceanic and Atmospheric Administration (NOAA) in Silver Spring, MD and in Berkeley, CA by the University of California, Berkeley. This series of meetings, animated progressively by the creative input of many people in the geospatial community, became the core of the development activity that evolved into the OpenGIS Project.

Based on these discussions and meetings, in late 1993, Kenn Gardels wrote a groundbreaking article on openness in the spatial domain, describing the concept of Open GIS [2]. The concept evolved into a vision of diverse geoprocessing systems communicating directly over networks by means of a set of open interfaces based on the "Open Geodata Interoperability Specification (OGIS)." OGF's "OGIS Project" was announced in June 1993.

Finally, the need for open interface and encoding standards led to another organizational change, because the OGF - a foundation - was not the right kind of organization to develop standards. Therefore, a 501 (c) 6 not-for-profit trade association was formed to replace the not-for-profit charitable foundation. The company was incorporated as "OGIS Ltd." on 25 August 1994. On 22 October 1994 Board resolution changed the name to "Open GIS Consortium, Inc." and then later, in 2004, the Board changed the name to "Open Geospatial Consortium."

A key financial enabler for the formation of the OGC Technical Committee consensus standards process was a cooperative agreement funded by US NASA. This agreement funded the OpenGIS Consortium, Bellcore, Rutgers, Camber Corp. (Huntsville, AL, USA), California Resource Agency's CERES, and NASA's Space Science Data Center to collaborate and create a working OGC Technical Committee process. The contract also helped the OGC bring new member organizations into the consortium. 
Throughout the early formative years of the OGC, a constant thread of requirements focused on the need for community consensus and processes that allowed many organizations to work together in a collaborative and collegial environment — even if the organizations competed in the market. Figure 1 shows a group picture for a 1998 OGC meeting in which consensus standards work occurred.

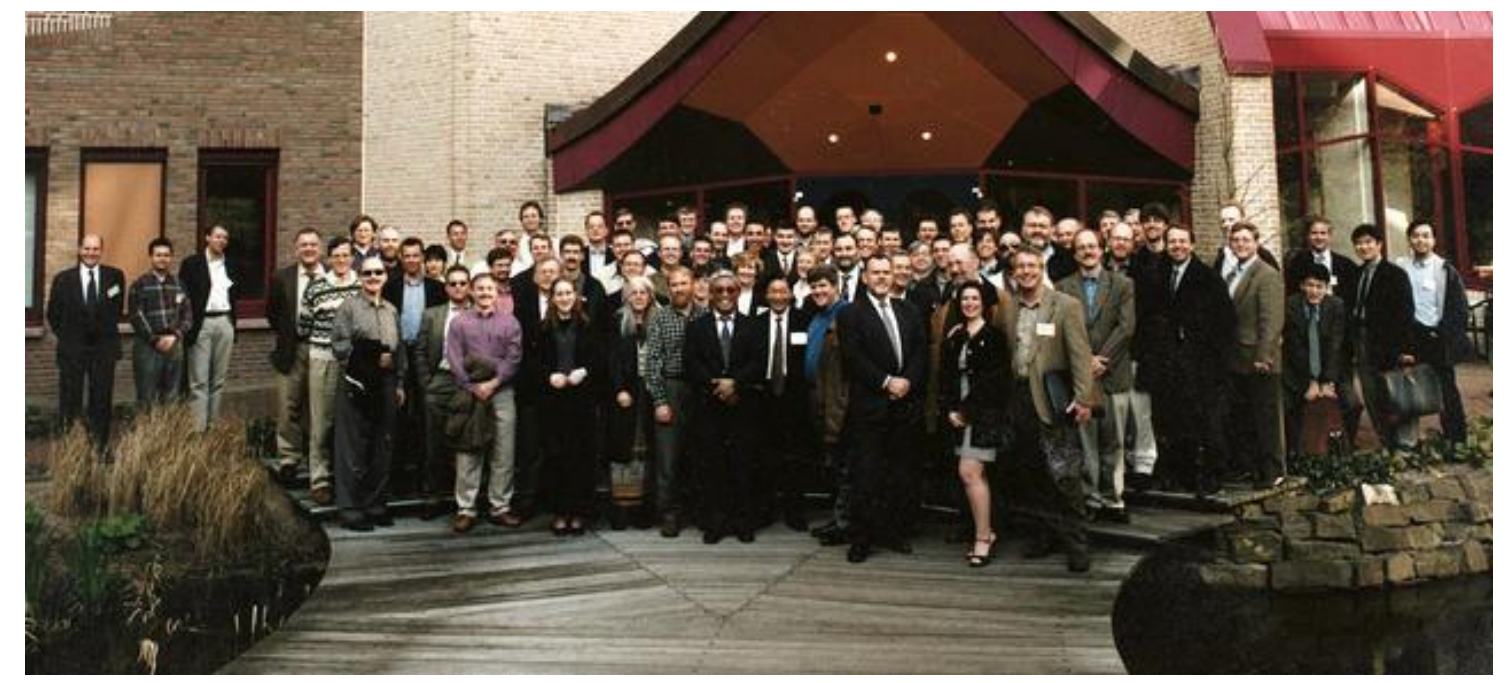

Figure 1. Early OGC Meeting, Enschede Netherlands 1998 [3].

\section{The OGC Interoperability Program: Major Enhancement to the OGC Standards Process}

For the first years of OGC standards work, the discussion and development of OGC standards progressed slowly and in a methodical—often called slow-and somewhat academic process. This process was what could be termed a traditional standards development process: develop the standard, approve, put in market and see who implements the standard.

In 1997, OGC staff and members began to discuss a rapid engineering and standards prototyping process. Much of this discussion occurred in the OGC Web Mapping Special Interest Group. In 1997, Doug Nebert expressed an interoperability requirement for standard that would allow a single browser instance to be able to access two or more distributed GIS servers from different vendors and create a single, integrated map image. Then he convinced the FGDC to provide funding to help offset the costs of such an interoperability activity_later called a testbed. Doug's question and the "sponsor" dollars from NIMA, FGDC, TEC, USAEC, USDA-NRCS, and NASA (US Department of Defense National Imagery and Mapping Agency (NIMA), US Army Corps of Engineers, Topographic Engineering Center (TEC), Federal Geographic Data Committee (FGDC), US NASA, US Department of Agriculture Natural Resources Conservation Service (USDA-NRCS)) gave rise to the Web Mapping Testbed Phase 1 (WMT1 (http://www.opengeospatial.org/projects/initiatives/wmt1)). This rapid prototyping initiative, which ran April through August 1998, produced the draft OGC Web Map Server (WMS) Interface Specification [4] and a very early version of the Geography Markup Language (GML) Encoding Specification [5].

Thus was started a powerful — and from a standards organization perspective — a unique way to accelerate the consensus standards development and testing process. Agile and rapid engineering of standards is now an integral part of the OGC standards development process. Today, sponsors — organizations with shared interoperability requirements-work together to document their requirements in use cases and a 
reality-based "grand challenge" scenario. Participants-IT providers, universities and research organization-provide a mix of compensated and in-kind resources to prototype and demonstrate candidate standards, best practices, compliance tests, reference implementations and proposed enhancements or revisions to existing standards. The results are better and more mature standards.

\section{What is Consensus in the OGC context?}

Consensus is a core value in the work of the OGC. Ask an OGC member what is meant by consensus and chances are that different individuals will provide slightly different answers. From time to time the OGC membership tries to define an exact definition for consensus - but cannot reach any agreement on a definition. What members will state is that the consensus process is guided by the OGC Technical Committee Policies and Procedures [6], which themselves are based on the key requirements for a voluntary consensus standards organization.

Wikipedia states:

Consensus decision-making is a group decision making process that seeks the consent of all participants. Consensus may be defined professionally as an acceptable resolution, one that can be supported, even if not the "favorite" of each individual.

From the OGC perspective, this is a strong operational definition and is instantiated in the working philosophy and policies of the standards development process. A very important aspect of this working definition is that all decisions do not need to be unanimous. While many decisions in the OGC are unanimous, a significant percentage of decisions are not unanimous. The ability to object and vote NO on any motion is a critical element of the OGC consensus process.

There is a rationale for this approach. First, participant consensus is critical to the adoption of standards. Second, the objective is to reach stable decisions. As such, significant - and often vigorous-discussion is a mandatory element of the OGC consensus process. A key part of such discussions is the ability to raise objections, play "devils' advocate", and state other viewpoints. For example, in 2007 the OGC Members had long and intense discussions regarding the role of the OASIS ebRIM (http://docs.oasis-open.org/regrep/v3.0/specs/regrep-rim-3.0-os.pdf) standard in the OGC. One group of members felt that ebRIM should be the only allowed catalog metamodel. Another group felt that this approach was too restrictive. The discussions occurred in emails, teleconferences, and ultimately at an OGC face-to-face meeting. Both groups debated their respective positions in various open forums, such as in Working Groups and to the full Membership. The OGC Technical Committee finally recommended that ebRIM be the OGC catalog metamodel. This recommendation went to the OGC Planning Committee. The Planning Committee reviewed the decision from a technical and business perspective. The PC decided that the TC recommendation was too restrictive and revised the technical motion to state that ebRIM was the preferred metamodel but that other approaches were equally valid (http://www.opengeospatial.org/pressroom/pressreleases/655). This was a wise decision as now the OGC Catalog Service Interface Standard [7] describes a variety of models and approaches, including OpenSearch. 
Such a consensus approach creates an environment in which all viewpoints are considered, discussed, and solutions agreed to. This approach leads to not just consensus but better standards. The downside is that developing a new standard can take longer than originally anticipated.

The implications of this approach are:

- A standard is supported by a consensus of members of the OGC community.

- Decisions are not strongly opposed by a sufficient subset of the members to cause them to be revisited.

- Unanimity is not a requirement for consensus.

- Silence is not interpreted as agreement.

- Significant objections are taken into account, and responded to.

- All opinions deserve a fair and equitable hearing and all comments deserve a complete and unbiased response.

- Before a vote is taken on any motion (anything subject to a vote), there must be an open, free, complete, fair and equitable debate,

- There is an appeals and adjudication process for resolving significant objections that cannot be resolved.

The belief in consensus as a foundation principal often means that standards development is not easy. Add in considerations such as the need for global collaboration between and among often competing organizations, different native languages and often competing requirements and the need for a certified, repeatable process becomes even more important.

Now consider how the OGC Policies and Procedures provide the framework for achieving consensus.

\section{The OGC TC Policies and Procedures and Consensus}

During the formation of the OGC, the group needed to figure out how to guide discussions, foster discussion, build consensus, process votes and motions, and so on. The OGC needed Policies and Procedures. The original ideas for the OGC Technical Committee Policies and Procedures (PnP) came from a review of how other standards organizations, such as the Object Management Group (OMG), developed standards. Kurt Buehler contacted Richard Soley, President of the Object Management Group, very early in the OGC formation process. Working with input from the OMG, early OGC members, legal counsel Andy Updegrove, and others the first version of the PnP was approved in 1995. Prior to the approval of the PnP, the OGC used Roberts Rules of Order. From Robert's Rules [8]:

Provides common rules and procedures for deliberation and debate in order to place the whole membership on the same footing and speaking the same language. Under no circumstances should "undue strictness" be allowed to intimidate members or limit full participation.

Roberts Rules of Order are still used as a guide for facilitating and managing discussions in the OGC process. Critical to the development of the OGC PnP was (and still is) the belief in creating and maintaining a fair and open process.

Revisiting the characteristics of a voluntary consensus standards organization, consider how these requirements are integrated into the OGC PnP. 


\subsection{Openness and Open}

A key element of the OGC philosophy as captured in the OGC policies and procedures. The concept and use of "Open" and "Openness" in the OGC has evolved considerably over the decades. Much of the evolution has been driven by market forces, including considerable input and dialogue with communities that are not OGC members. Discussions on what the OGC means by "open" began well before the organization was officially formed. There was a real concern about being both fair and open. This concern and related discussions continue to this day.

The OGC uses both terms: Open and Openness. Open tends to refer to "open standards" whereas Openness tends to refer to how open the OGC standards process is to all concerned individuals and constituents.

Andy Updegrove, OGC Counsel, in a 2012 article wrote [9], “"open standards', implying openness in not only the process under which the standard was created, but also the transparency of that process, and ensuring the availability of any patented technology necessary to implement the standard on fair and reasonable, non-discriminatory (FRAND, or in the U.S. just RAND) terms" (see Section 7 below for more information on these terms). As a voluntary consensus standards organization, the OGC abides by these "rules" for open standards.

Over the years, many have complained about the "openness" of the OGC processes: Only members could participate, discuss standards development issues, and vote. While anyone could (and can) join the OGC and participate, the OGC is a Membership organization whose annual membership fees fund the operation. However, given input from both Member and non-Member organizations, the OGC has become much more open and transparent. The latest intense dialogue about how the OGC can be more open, transparent, and responsive to market needs occurred in late 2013 into 2014. Called "Ideas4OGC", the OGC had numerous web conferences to solicit and clarify community requirements and suggested policy changes to help make the OGC a more open and transparent standards organization. Ideas4OGC (http://external.opengeospatial.org/twiki_public/Ideas4OGC/WebHome) was the latest activity to bring necessary community input into the process.

Since 1994, the OGC has made numerous changes to their policies and procedures to be more open and transparent. A number of positive changes include:

- Domain Working Groups may be public. This means that anyone, Member or non-Member, can subscribe to the email list and participate in discussions.

- Anyone can submit change requests and requirements into the OGC standards process (https://portal.opengeospatial.org/public_ogc/change_request.php).

- The results of all OGC document votes and motions are publicly announced.

- OGC Interoperability Experiments can include non-Member organizations.

- All planned standards development activities are publicly announced and the draft charter is made available for public comment.

- All OGC standards documents are made publicly available for review and comment prior to any approval votes.

- A number of OGC Standards Working Groups are now using GitHub as a collaboration platform thus allowing non-Member developers access to in-progress candidate standards. 
At the same time, the concept of what an OGC "open standard" has evolved. The current OGC guiding framework for the definition an Open Standard is a format or protocol that is:

1. Subject to full public assessment and use without constraints in a manner equally available to all parties;

2. Without any components or extensions that have dependencies on formats or protocols that do not meet the definition of an Open Standard themselves;

3. Free from legal or technical clauses that limit its utilization by any party or in any business model;

4. Managed and further developed independently of any single vendor in a process open to the equal participation of competitors and third parties;

5. Available in multiple complete implementations by competing vendors, or as a complete implementation equally available to all parties.

If this definition looks familiar this is because the Free Software Foundation Europe (FSFE) uses this definition which is based on the European Interoperability Framework v.1.

\subsection{Balance of Interest}

A key aspect of consensus and openness is achieving and ensuring a balance of interest. In the OGC, balance of interest means that no single organization or small group of commercially aligned special interests can "hijack" the OGC standards setting process and potentially violate the OGC premise of openness, fairness, and open standards. To this end, the OGC PnP has rules and guidance that includes:

- Technology Submission: While a single organization can submit technology for consideration as an OGC standard, such submissions require that three or more different OGC member organizations support the submission. Further, the submitting organization agrees to sign a legal document transferring all intellectual property to the OGC.

- New standards activity: While a single organization can propose a new standards activity, three or more different OGC member organizations shall agree to support this activity. Further, the team must write a charter that describes the work to be performed. This charter is made publicly available for review and comment. Finally, the OGC Members vote to approve — or not — the new standards activity.

- All Member organizations, regardless of membership level, have an equal voice in the development of an OGC standard. This includes all discussions and motions related to the development of an OGC standard. This means that a small company or a university can have the same impact as a Fortune 100 company or large government organization.

The OGC constantly strives to make sure all points of view are heard and part of the consensus decision process.

\subsection{Due Process}

Due process in a standards organization is guided by its policies and procedures. The policies and procedures define the rules and processes related to how standards technology is submitted, reviewed, edited, and approved (voting). Policies and procedures typically also speak to the structure of the 
standards organization, how groups are formed, how these groups conduct business, and how groups are dissolved. Finally, the policies and procedures define roles and responsibilities in the standards organization, such as those for group chairs, document editors, and facilitators.

The OGC has several related Policies and Procedures documents:

- OGC Bylaws [10]-Maintained and approved by the OGC Board of Directors. This document provides the governance framework for the OGC, including the structure of the organization and rules of membership.

- Technical Committee Policies and Procedures: Documents all TC voting processes and procedures; Documents the formation, scope and processes required for TC subgroup and committee activities; Documents the processes and procedures for submitting, reviewing, and approving a new standards using the Request for Comment procedures; Documents the process for revisions to adopted OGC standards. The Technical Committee is granted authority to operate by the OGC Bylaws.

- OGC Architecture Board Policies and Procedures [11]: The mission of the OAB is to provide a forum within which Consortium wide standards architecture issues can be discussed and deliberated with the intent of providing guidance and recommendations to the TC and the Planning Committee on these issues. In order to properly provide such guidance and perform the Governance functions as outlined below, the $\mathrm{OAB}$ can, at its discretion, evaluate current technology issues and identify gaps in the architecture that need to be responded to by the Membership.

- OGC Naming Authority Policies and Procedures [12]: The OGC Naming Authority (OGC-NA) controls the assignment of OGC Names to resources of interest in geographic information infrastructures. In the terminology defined in ISO 19135, OGC-NA is the Control Body for the register of OGC Names. The PnP document describes the framework of documents, registers and other resources required for OGC-NA to execute that role. There are separate OGC-NA Policies and Procedures.

As the needs and purpose of the TC change, policies and procedures changes are approved by an electronic vote of the Voting Members of OGC TC or by recommendation of the OGC Planning Committee. The Members "own" the policies and procedures. The majority of suggested changes to the PnP are made by the OGC Membership and often supported by market forces and the developer community.

One underlying characteristic of all of the PnPs is the role that intellectual property has in the definition and enforcement of the policies. This topic is addressed later in this paper.

\subsection{Appeals Process}

No standards organization conducts business without the occasional argument or conflict that cannot be resolved within the normal PnP framework and consensus process. These conflicts can arise from different interpretations of the policies and procedures, disagreement over a group decision, concern over violation of the balance of interest requirement, and so on. In these cases, a formal appeals process 
and conflict resolution process and related policies are required. In the OGC, there are perhaps one such appeal or conflict every two years - not often but still requiring a formal process to resolve the conflict.

The OGC has a formal conflict resolution and appeals process. This process includes an escalation process. If one or more Member organizations wish to appeal a decision or misuse of the OGC process, they shall:

- Notify the TC Chair of their intent to file an appeal;

- Write a formal appeals document stating the conflict and their suggested resolution. This document is made available to the entire membership;

- The TC Chair coordinates with the OGC Architecture Board. The OAB is the formal OGC body to initially "hear" the complaint/appeal.

- The OAB reviews the appeal and meets to discuss the appeal. The result is the OAB provides guidance to the group that submitted the appeal. If the group accepts the guidance and resolution, then the appeals process is complete. Otherwise the issue is escalated to the OGC Planning Committee.

- If the group does not accept the OAB guidance, then the appeal is escalated to the OGC Planning Committee.

- The Planning Committee reviews the appeal and provides guidance. The guidance could be to endorse the $\mathrm{OAB}$ guidance and/or to provide additional guidance. If the group accepts the guidance and resolution, then the appeals process is complete. Otherwise the issue is escalated to the OGC Board of Directors.

- If the group does not accept the OAB guidance, then the appeal is escalated to the OGC Board of Directors (BoD).

- The BoD reviews the appeal and provides guidance. End of process.

If by the end of the appeals process, the group that submitted the appeal still does not agree with the decision or guidance they can marshal other OGC Members to vote "No" on the motion or document approval vote that started the whole appeals process. In the twenty years of standards development work, this last case has happened just once. All in all, the OGC community is extremely collegial and resolves the vast majority of conflicts or differences in a working group - or over a beer after a meeting.

\subsection{Consensus}

In Section 4 above, the OGC concept and approach to consensus was discussed. However, one key aspect of consensus was not presented: Voting. The voting process and procedures in a standards organization encapsulate and define member consensus in a very formal way. In the OGC, motions and votes happen on a very regular basis. Any OGC member in good standing can participate in the definition, discussion, and approval (The only exception is for official votes on the adoption of an OGC standard, best practice, or policies and procedures. Only Voting Member organizations can vote on these official motions) (or not) of a motion. Examples of motions and votes are:

- Approval of a new work activity;

- Approval of a Working Group Charter;

- Approval to release a document to the public; 
- Approval of a proposed change request to an existing OGC standard;

- Approval of a new OGC standard.

The TC PnP provides guidance on all voting procedures in the OGC. Essentially, there are two primary forums for voting: (1) At a face to face meeting and (2) electronic votes. In both cases there are rules regarding quorum, sufficiency, and approval. The majority of non-electronic votes, such as at a face to face meeting, are based on a simple majority of those present (unless there are quorum rules in effect). Typically, these motions are in the form, "Is there any objection to unanimous consent". If there is objection, then a hand vote is held and the results recorded.

Any motion can request an electronic vote. Certain votes, such as approving a new OGC standard, require and e-vote. Electronic votes are very formal and have a well-defined structure and process. All such votes must be announced to the entire membership. There are strict quorum rules, a fixed duration, and strict rules on sufficiency and approval. In the OGC, one characteristic of consensus is that unanimity is not required. There can be a number of "No" votes and the motion will still pass. The caveat is that any comments received during a formal e-vote must be considered and formally responded to.

\section{Consensus and Intellectual Property}

At the core of the OGC standards work is how intellectual property (IPR) is dealt with in the consensus process. The OGC Intellectual Property Policies and Procedures (http://www.opengeospatial.org/about/ipr) documents the OGC policy regarding IPR. In essence, the OGC IPR policy and its expression in the TC Policies and Procedures is designed to ensure as best as possible that OGC standards are not encumbered with 3rd party IPR or patents or other claims and that all OGC standards remain available on a reasonable and non-discriminatory basis (RAND). Further, in the 20 year history of the OGC, all OGC standards have been made available on a Royalty Free (RF) basis.

Specifically, the OGC IPR policies state that:

- Any OGC member shall declare any essential claims related to a candidate standard during the standards development process;

- Any OGC member who is aware of patents that may be infringed during the development of a standard shall notify the OGC of this possible infringement;

- Any OGC member submitting standards technology into the OGC standards process agrees to transfer all copyright and intellectual property related to that candidate standard to the OGC;

- If there are license requirements, the member(s) shall provide reasonable and non-discriminatory (RAND) terms (this has never happened in the OGC)

- All Members, all Member Representatives, and all third parties attending any technical process meeting are subject to the IPR PnP. Members and their Representatives are so bound under the terms of the OGC membership application, and all third parties shall be required to sign an appropriate acknowledgement of the foregoing as a precondition to participating in the OGC technical process.

As a result of the OGCs commitment to the consensus process coupled with the desire to keep all OGC standards available under RAND-RF terms, there have not been any patent or infringement issues related to OGC standards since 2002. In 2002, there was an issue with the OGC Web Map Service 
Interface Specification. A British company and a Japanese company both stated that the OGC WMS standard infringed on their web mapping patents. These companies were not OGC Members. In response, the OGC was (1) able to show that OGC web mapping publications predated the patents and (2) the OGC Members reviewed their own product and research archives and discovered numerous instances of web mapping applications that predated the patents by many years. This research was captured and published in [13].

\section{What is the OGC View of a Successful Standard?}

While the topic of this paper is on the OGC and its open, consensus process the title does make the statement, "How Successful Standards Are Made". From the OGC perspective, the answer is quite simple: Is the standard implemented? The OGC tracks whether their standards are implemented or not. There are numerous measures, including number of downloads from the OGC website over a given period of time that OGC staff and Members can view. There is also a catalog of information (http://www.opengeospatial.org/resource/products) on implementing products and applications. This is provided on a voluntary basis. Any organization, whether an OGC member or not, can provide implementing product information. There are also a number of applications that look for and report on active OGC web service instances (http://www.opengeospatial.org/blog/2034). All of this information is used by the OGC and the OGC Membership to determine whether an OGC standard is being implemented or whether a particular standard or version of a standard should be retired.

Finally, from the OGC Member perspective, a successful standard is one in which anyone can participate in the development of that standard, where they can provide requirements and use cases, and vote on approving that standard (or not). Success is based on discussion, consensus, member approval, and then ultimately implementation in the marketplace.

\section{What has been Established and What's Next?}

Just over a year ago several major standards organizations collaborated and agreed to a set of principles that should guide both standards development as well as how various standards organizations work together. OpenStand (https://open-stand.org/) Modern Paradigm for Standards, signed by the IEEE, IETF, IAB, Internet Society and W3C is shaped by adherence to the following five principles: Cooperation, Adherence to Principles, Collective Empowerment, Availability, and Voluntary Adoption. The OGC adheres to these five principals. In addition there is the Adherence to Principals of development.

Similar to the characteristics of a voluntary consensus standards organization, the adherence to the five fundamental principles of standards development:

- Due process. Decisions are made with equity and fairness among participants. No one party dominates or guides standards development. Standards processes are transparent and opportunities exist to appeal decisions. Processes for periodic standards review and updating are well defined.

- Broad consensus. Processes allow for all views to be considered and addressed, such that agreement can be found across a range of interests.

- Transparency. Standards organizations provide advance public notice of proposed standards development activities, the scope of work to be undertaken, and conditions for participation. 
Easily accessible records of decisions and the materials used in reaching those decisions are provided. Public comment periods are provided before final standards approval and adoption.

- Balance. Standards activities are not exclusively dominated by any particular person, company or interest group.

- Openness. Standards processes are open to all interested and informed parties.

The OGC has evolved over the years to the point where their consensus process and operational policies incorporate all of the characteristics and requirements as stated in the five fundamental principles for standards development.

\section{Summary}

The OGC consensus process is constantly evolving to reflect Member, market, procurement, and implementer requirements. The Policies and Procedures that guide the open, consensus process continually evolve and are updated. As with any official OGC document, revisions to the Policies and Procedures require discussion and agreement and ultimately a formal vote by the Members to approve those revisions. Since 1994, the TC PnP has gone through 20 revisions. The latest revision was approved in June 2015. Many of the changes in that version reflect discussions from the Ideas4OGC activity. The OGC continues to strive to provide an open, transparent consensus process. If you have any suggestions on how the OGC can make there consensus process better, please contact the OGC.

\section{Author Contributions}

Carl Reed is the editor and major contributor. Kurt Buehler provided details of the early history of the OGC and did a review of the document. Lance McKee provided input on all historical aspects of the OGC and did a review and edit of the document.

\section{Conflicts of Interest}

The authors declare no conflict of interest.

\section{References}

1. Federal Participation in the Development and Use of Voluntary Consensus Standards and in Conformity Assessment Activities. Available online: http://www.whitehouse.gov/omb/circulars_a119 (accessed on 12 July 2015).

2. Gardels, K. Defining open GIS: An introduction to the open geodata interoperability specification. grass clippings. J. Open GIS 1993, 7, 7-9.

3. OGC Picture Archives. Available online: http://photos.opengeospatial.org/gallery/index.php/ Enschede-1999/\# (accessed on 05 August 2015)

4. OGC Web Map Service Interface Specification Version 1.0. OGC 00-0028. 2000. Available online: http://portal.opengeospatial.org/files/?artifact_id=7196 (accessed on 12 July 2015).

5. OGC. Geography Markup Language Encoding Standard. Available online: http://www.opengeospatial.org/standards/gml (accessed on 12 July 2015).

6. OGC. Technical Committee Policies and Procedures; Reed, C., Ed.; OGC: Wayland, MA, USA, 2015. 
7. OGC. Catalog Service Interface Specification. Available online: http://www.opengeospatial.org/ standards/cat (accessed on 12 July 2015).

8. Roberts Rules of Order online. Available online: http://www.rulesonline.com/ (accessed on 05 August 2015).

9. Updegrove, A. Openness and legitimacy in standards development. In Proceedings of the First Openforum Academy Conference, Brussels, Belgium, 11 November 2012.

10. OGC Bylaws. Available online: http://portal.opengeospatial.org/files/?artifact_id=6947 (accessed on 12 July 2015).

11. OGC Architecture Board. OAB Policies and Procedures; Reed, C., Ed.; OGC: Wayland, MA, USA, 2010.

12. OGC Naming Authority. Policies and Procedures; Cox, S., Ed.; OGC: Wayland, MA, USA, 2010.

13. Reed, C. Intellectual property, patents and web mapping: A historical perspective on claiming innovation. Int. Soc. Photogramm. Remote Sens. 2003, 8, 33-35.

(C) 2015 by the authors; licensee MDPI, Basel, Switzerland. This article is an open access article distributed under the terms and conditions of the Creative Commons Attribution license (http://creativecommons.org/licenses/by/4.0/). 